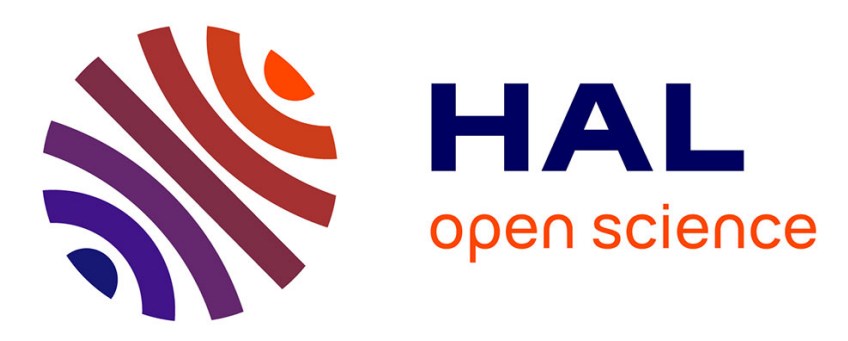

\title{
Brood size can influence maternal behaviour and chick's development in precocial birds
}

Nadège Aigueperse, Florent Pittet, Emmanuel de Margerie, Céline Nicolle, Cécilia Houdelier, Sophie Lumineau

\section{- To cite this version:}

Nadège Aigueperse, Florent Pittet, Emmanuel de Margerie, Céline Nicolle, Cécilia Houdelier, et al.. Brood size can influence maternal behaviour and chick's development in precocial birds. Behavioural Processes, 2017, 138, pp.96-104. 10.1016/j.beproc.2017.02.018 . hal-01490372

HAL Id: hal-01490372 https://hal-univ-rennes1.archives-ouvertes.fr/hal-01490372

Submitted on 12 Jul 2017

HAL is a multi-disciplinary open access archive for the deposit and dissemination of scientific research documents, whether they are published or not. The documents may come from teaching and research institutions in France or abroad, or from public or private research centers.
L'archive ouverte pluridisciplinaire HAL, est destinée au dépôt et à la diffusion de documents scientifiques de niveau recherche, publiés ou non, émanant des établissements d'enseignement et de recherche français ou étrangers, des laboratoires publics ou privés. 
Brood size can influence maternal behaviour and chick's development in precocial birds.

Nadège Aigueperse ${ }^{1,2}$, Florent Pittet ${ }^{1,2}$, Emmanuel de Margerie $^{1,2}$, Céline Nicolle ${ }^{1,2}$, Cécilia Houdelier ${ }^{1,2}, \&$ Sophie Lumineau ${ }^{1,2}$ (corresponding author)

(1) Université de Rennes 1, UMR 6552 Ethologie animale et humaine, Rennes, France.

(2) CNRS, UMR 6552 Ethologie animale et humaine, Rennes, France

Corresponding author: S. Lumineau, UMR CNRS 6552 Ethologie Animale et Humaine, Université de Rennes I, Bâtiment 25, Campus de Beaulieu, 263 Avenue du Général Leclerc, CS74205, 35042 Rennes, France. E-mail address: sophie.lumineau@univ-rennes1.fr

Highlight:

- Mothers quails were observed with $6(\mathrm{~N}=9)$ or 3 chicks $(\mathrm{N}=9)$.

- Chicks' emotivity and sociality were analysed with behavioural tests.

- Large brood enhance maternal behaviour at the beginning of the mothering.

- Chicks of large brood were rejected earlier by mothers.

- Brood size influence the thermoregulation strategy and social development of chicks. 


\section{Abstract}

Mothers have a crucial influence on offspring development. Variations of maternal behaviour can be due to numerous parameters, for instance costs are related to the size of a brood/litter, which in turn can influence the level of mothers' investment in each offspring. Here we investigated the influence of brood size on the behaviour of Japanese quail mothers and chicks during the mothering period and on offspring development. We compared two types of broods: small broods of three chicks $(\mathrm{N}=9)$ and large broods of six chicks $(\mathrm{N}=9)$. Behavioural tests assessed chicks' social and emotional traits. Mothers of large broods emitted more maternal vocalisations at the beginning of the mothering period, but at the end they assumed more non-covering postures and trampled chicks more than mothers of small broods. Chicks in large broods huddled up more whereas chicks in small broods rested alone more frequently. Moreover, the social motivation of chicks in large broods was higher than that of chicks in small broods, although their emotional reactivity levels were similar. Our results evidence the importance of brood size for maintaining family cohesion and the influence of brood size on chicks' interactions with their siblings. We evaluated the influence of mothers and siblings on chicks' behavioural development.

Key-words: maternal vocalisations, mothering period, social development, warming strategy.

\section{Introduction}

Parental care is essential for the survival of the young of many species. Only mothers of $90 \%$ of mammal species and of most of the precocial bird species take care of the offspring (Royle et al. 2012). Precocial chicks forage by themselves and the primary role of their parents is to provide them with heat, necessary for their thermoregulation during early post-hatching stages (Webb 1993). Maternal behaviour is known to influence chicks' behavioural development and precocial bird mothers can influence their chicks' emotional and social traits through non-genetic postnatal mechanisms inducing both long term and transgenerational consequences (for a review: Houdelier et al. 2013). For example, social deprivation of 
mother impairs Japanese quail's social motivation and increases aggressiveness (Richard-Yris and Bertin 2005) and emotional reactivity (Pittet et al. 2013a). Moreover, mothers can transmit some of their behavioural traits by their maternal style (Pittet et al. 2014a). Understanding maternal influences on behavioural development is essential given their consequences on subsequent survival as individual characteristics like exploration, aggressiveness or emotionality are related to adult survival and adaptation to environmental variations (Dingemanse et al. 2004; Cockrem 2007). For example, reactive individuals, defined as passive, motionless and shy during stressful events adapt better to unstable situations, whereas proactive individuals, defined as active, aggressive and bold do better in stable situations (Koolhaas et al. 2001, Cockrem 2007).

Maternal care can vary within the same species according to environmental or individual factors such as age, reproductive experience or temperament (Champagne et al. 2003; Angelier et al. 2007; Pittet et al. 2012; Lopatina et al. 2011). Offspring can influence their mothers' care by their behaviour (Smiseth and Moore 2002) or their sex (Harding et al. 2009; Pitts et al. 2002). Moreover, mammals' and altricial birds' maternal care varies with the number of their offspring. For instance, rodent mothers spend less time with their offspring when their litters are large (rats: Grota and Ader 1969; gerbils: Elwood and Broom 1978). Furthermore, the quality of maternal care differs with litter size: gerbils lick more pups in large litters (Elwood and Broom 1978), while mice lick less pups in large litters (Priestnall 1972). The effects of brood size on altricial birds' maternal care are estimated mainly by the time spent in the nest or by the level of food-provisioning (Royama 1966; Walsh 1978; Johnson and Best 1982; Yasukawa et al. 1990): harrier or starling mothers with large broods spend less time at their nest but provision chicks with more food than do parents of small broods (starlings: Clark 1985; harriers: Leckie et al. 2008). However, despite an increase in food supply, the intake rate per chick remains similar or is even lower than that of starlings in small broods (Wright and Cuthill 1990). The few studies that address the effects of the size of precocial birds' broods focus on offspring survival more than on maternal care. Field studies show that increase in brood size can induce either negative (sandpipers: Safriel 1975) or positive effects (snow geese: Lepage et al. 1998) or have no effect (willow 
ptarmigans: Sandercock 1994) on offspring survival and quality. The time mothers spend being vigilant increases with brood size (lapwings: Walter 1982; lesser snow geese: Williams et al. 1994), or are more aggressive (bar-headed geese: Schindler and Lamprecht 1987). These results of field studies concerning biparental species could be the consequences of interactions between environmental and social factors (Lepage et al. 1998).

Behavioural development is not only influenced by mothers but also by broodmates. The emotivity and sociality of non-brooded chicks are modified by group size, but the subsequent effects remain unclear. Generally, the larger the group, the more chicks react to social separation or to a decrease in group size by emitting distress calls (ducks: Gaioni et al. 1977; chicks: Jones and Harvey 1987), although social bonds are stronger in small groups (quail: Schweitzer et al. 2011). However aggressiveness increases in large groups of chicks or adults and enhances individual emotional reactivity (review in Rodenburg and Koene 2007). Large broods reduce altricial parents' thermoregulation investment as nests retain heat better (Webb and King 1983; Guerra and Nunes 2001; Leckie et al. 2008). However, the effects of brood size of precocial bird family groups (a mother with a brood) either on maternal behaviour or on chicks' behavioural development have not yet been investigated.

Our study investigates for the first time the influence of brood size on Japanese quail's (Coturnix coturnix japonica) maternal behaviour and on mothers' interactions with chicks. The maternal behaviour of mothers of this precocial species presents important inter-individual variability (Pittet et al. 2014a), depending on mothers' traits (Pittet et al. 2012, 2013a, 2013b, 2014a). Although reports suggest that brood size influences chicks' survival and quality, to our knowledge, the influence of brood size and chicks' behaviour on maternal behaviour traits and on the interactions between mothers and chicks has not been investigated in detail. We hypothesized that mothers of large broods would express more maternal care as a consequence of more solicitations from their brood. Vocal and tactile stimulations are known to play an important role in inducting and maintaining maternal behaviour (Richard-Yris 1994). Moreover, we predicted that mothers of large brood would reject their chicks sooner because chicks can huddle together more easily thus enhancing their thermoregulation. Considering that mothering differs with brood size, and that broodmates influence chicks' behavioural development 
directly, we hypothesized that brood size would influence the development of chicks' behavioural and in particular their social traits.

2. Material and methods

\subsection{Ethical note}

All our experiments were approved by the departmental direction of veterinary services (Ille-et-Vilaine, France, permit number 005283) and were realised in accordance with the European Communities Council Directive of 24 November 1986 (86/609/EEC). The breeding procedure and tests were approved by the regional ethics committee (agreement number: R-2011-SLU-02).

\subsection{Subjects and housing conditions}

\subsubsection{Adoptive mothers}

All adult quails (Coturnix coturnix japonica) came from an industrial farm (Les cailles de Chanteloup, Corps-Nuds, France). Twenty 43-week-old naive female quail became adoptive mothers. They were placed in individual cages $(100 \mathrm{~cm} \times 70 \mathrm{~cm} \times 62 \mathrm{~cm})$ in a single room, 3 weeks before the start of the mothering experiment, for habituation. Female quail incubate and breed their chicks alone (Guyomarc'h and Saint Jalme 1986). The room was maintained under a LD 12:12 cycle and at $23 \pm 1^{\circ} \mathrm{C}$. Quail had access to food (80cm-long feeder, high protein cereal in pellets) and water ad libitum. During this habituation period, for their well-being, females had access to square plastic boxes $(19 \times 19 \times 7 \mathrm{~cm})$ filled with wood shavings to dust-bathe 3 times a week. This enrichment was not used during the mothering period as it would have impeded observations.

\subsubsection{Chicks}

Chicks came from eggs artificially incubated in the laboratory. These eggs were collected during 1 week from 45 females and nine males (from previous experiments). We placed 80 eggs in an incubator for 17 days $\left(37.7^{\circ} \mathrm{C}, 55 \%\right.$ of humidity and two $45^{\circ}$ rotations per day). After hatching, chicks were placed in three plastic cages $(49 \mathrm{~cm} \times 35 \mathrm{~cm} \times 42 \mathrm{~cm})$. Each cage was equipped with a heater (60W IR lamp bulb) and food (high protein cereal in mixed pellets) and water were provided ad libitum. Chicks stayed in 
these cages during their first Post-Hatching Day (PHD1) before being placed with foster mothers in the evening. Chicks were weighed at birth and once a week for 5 weeks.

\subsubsection{Brood constitution}

Under natural conditions, female quail lay between five and ten eggs, one per day (Taka-Tsukasa 1935). We constituted two types of broods: 10 large broods (L), each including six chicks and an adoptive female; and 10 small broods (S) each containing three chicks and an adoptive female. We chose 3 as the minimum size to limit the problem of sex effects (we had only one cage with only females). We then chose 6 to maximize brood size difference (doubling the effective), this number was limited by the size of the cage and technical observation constraints. The relationships between chicks in groups of more than 6 chicks become more complex (Schweitzer et al. 2011). All chicks were identified with coloured rings around their legs and three chicks from each cage (randomly selected from the L broods) were observed throughout the experiment.

At the end of the 11 days of the mothering period, the mothers were removed from the cages and placed together in another room $\left(4 \mathrm{~m}^{2}\right)$ with floor covered with wood shavings before being involved in another experiment. Chicks remained in sibling groups in their home cages for four more weeks during which their behaviour was assessed by ethological tests. They were given the opportunity to dust-bathe as bath boxes were provided 3 times a week.

The sex of chicks was determined by feather colour when they were 6 weeks old when sexual dimorphism becomes clear. Sex ratios (Sex ratio: $\mathrm{L}=0.89, \mathrm{~S}=0.69$; Chi square test: $\mathrm{X}^{2}=0.58, \mathrm{P}=0.45$ ), and birth weights $\left(\mathrm{L}=10.82 \mathrm{~g} \pm 0.12 \mathrm{SE}, \mathrm{S}=11.05 \mathrm{~g} \pm 0.16 \mathrm{SE}\right.$, Mann-Whitney test: $\mathrm{U}=1537 \mathrm{~N}_{\mathrm{L}}=60$, $\mathrm{N}_{\mathrm{S}}=30, \mathrm{P}=0.14$ ) did not differ significantly between groups.

\subsection{Maternal induction procedure}

We used adoptive mothers to control genetic constraints such as maternal effects or relatedness, which could interfere with the expression of maternal behaviour. We followed the maternal induction procedure finalized by Richard-Yris (1994). The evening chicks hatch, mother quail were locked up in individual plastic nest-boxes $(18 \mathrm{~cm} \times 18 \mathrm{~cm} \times 18 \mathrm{~cm})$ for one hour before lights were switched off. When 
lights had been switched off, we placed either 3 or 6 chicks delicately under each female in each nestbox. The next morning, we opened and removed the boxes delicately from the rearing cages. Then, using instantaneous scan sampling, we recorded every 15 minutes for three hours, the mothers' behaviour towards chicks to control that the females warmed their chicks and did not aggress (attacks, pecks) or reject them (contact breaks, ineffective warming postures). When a chick showed signs of discomfort or hypothermia (shivering, closed eyes, motionless), we removed it immediately from its mother's cage and placed it in a plastic cage $(98 \times 35 \times 42 \mathrm{~cm})$ under a heater where it recovered swiftly (in less than 1 hour). To keep brood sizes stable throughout the experiment, these removed chicks were replaced by chicks of the same age throughout the experiment. Observations of chicks used for replacements after PHD3 were not included in subsequent analyses. Two adoptive females (one from each set) expressed no maternal care following induction and were thus were not included in the experiment. In all 20 chicks had to be replaced during the mothering period $(L=7, S=13)$.

\subsection{Observations of mothers' and chicks' behaviours}

\subsubsection{Maternal behaviour}

We used two methods to assess maternal behaviour (Pittet et al. 2014a): instantaneous scan sampling to establish time-budgets and focal sampling for occasional behaviours. Scans were recorded using an iPod Touch (AppleC) running the application "scan sampling" (Vincent Richard(C). We recorded two sessions of 30 scans each (at 7-minute intervals) and 10mn focal sampling each day. These observations were made on PHD2 (afternoon), PHD3, PHD5, PHD7 and PHD9 (morning and afternoon) (Fig 1). Behaviours recorded are listed and described in Table 1.

In addition, the number of chicks warmed (under the mother, estimated by subtracting the number of chicks elsewhere in the cage from the total number in the brood) allowed us to calculate an index of

chicks being warmed (PWC): $P W C=\frac{\sum_{k=1}^{n}\left(\frac{k}{n} \times N W k\right)}{N W}$ with: 
PWC: proportion of chicks being warmed

n: brood size

$\mathrm{k}$ : number of chicks being warmed.

NWk: number of scans when $\mathrm{k}$ chicks were being warmed

NW: total number of scans when chicks were being warmed

\subsubsection{Maternal reactions to separation}

On PHD11, we took all the chicks out of their cage for 5 minutes and recorded their lone mother's reactions: latency of first comfort behaviour (feeding, rest or maintenance), latency of first call and the total number of calls.

\subsubsection{Chicks' behaviour in their home cage}

The behaviour of the three focal chicks in each brood was recorded on PHD4, PHD6, PHD8 and PHD10 and, after the end of the mothering period, on PHD15 and PHD22. Their behaviour was recorded by 30 instantaneous scan samplings (15 in the morning, 15 in the afternoon, at 7-minute intervals). Behaviours recorded are detailed in table 1. In addition we estimated the dispersal of the brood in the cage (divided into 6 sections) and calculated an index of dispersion based on the number of cage sections occupied by the three focal chicks based on a dispersion score ( 0 when the three chicks were in the same section, 0.5 when they occupied two different sections and 1 when they were in three different sections) for each scan. An average dispersal score was calculated for each observation day by adding all scores and dividing by the number of scans.

\subsection{Chicks' behavioural traits}

The temperaments of the three focal chicks in each cage were assessed using well established ethological procedures assessing fear and social reactivity in different contexts. The chronology of these tests is presented in Figure 1. 
Separation from siblings. To evaluate the strength of the social bond between chicks (Pittet et al. 2012), when chicks were 16 days old and no longer with their mother, we removed all chicks except one for 3 minutes. We recorded latencies of first distress call and of first step, frequencies of calls and steps, and time spent eating. Then, we replaced the removed chicks, and after 15 min, we tested another chick, and then the third chick.

Emergence test. This test assesses the 'shyness'/'boldness' of an individual and its sociality in a novel open environment and in social isolation (Jones 1987). On PHD19 chicks were placed individually, for one minute, in a small, dark wooden box $(18 \times 18 \times 18 \mathrm{~cm})$ placed next to the entrance of a larger, lighted wooden test cage $(62 \times 60 \times 30 \mathrm{~cm})$ with wood shavings on the ground. After opening a door between the boxes, the experimenter recorded latencies to pass head and whole body out of the smaller box, latency of first distress call, number of calls in the large box during 3 minutes (exploration, observation, fear postures, pacing).

Runway. This test evaluates the motivation of a subject to reach a social stimulus and was performed on PHD23 (Mills and Faure, 1991). The apparatus was a long corridor $(150 \times 20 \times 20 \mathrm{~cm})$ with a cage $(20 \times 35 \times 20 \mathrm{~cm})$ at one end containing two unfamiliar chicks of the same age as the test chick. The test chick was placed in a small wooden box $(18 \times 18 \times 18 \mathrm{~cm})$ at the other end. The box was kept closed for 1 minute and then it was opened: we recorded latency to leave the small box and once out, the box was delicately closed again. The tunnel was divided into four virtual segments, with, starting from the test chick's end: zones A, B, C $(32 \mathrm{~cm})$ and P $(14 \mathrm{~cm}$, the part near the social stimulus). For 3 minutes, we recorded the time to reach the $\mathrm{P}$ zone, the time spent in each zone, latency of first call, and the number of attempts to reach conspecifics and to peck the cage.

Openfield test \& novel object (Jones et al. 1982). On PHD25 and PHD26 we placed, manually and in the dark, a test chick in the centre of an unfamiliar arena $(\varnothing 120 \mathrm{~cm}, \mathrm{H} 60 \mathrm{~cm})$ with a linoleum floor and white plastic walls. Then the light was switched on and the experimenter, hidden behind a one-way mirror, recorded for 3 minutes, latencies of first step and of first distress call, and the frequencies of observation postures (high and low) and of fear behaviours: freezing (head back into body, feathers 
puffed, body frozen) pacing (stereotyped roundtrips along a wall with some jumps). Then we placed, in the dark, an unfamiliar object (a brown cylinder, $\varnothing 7 \mathrm{~cm}, \mathrm{H} 15 \mathrm{~cm}$ ) on a side of the arena, opposite the chick. We illuminated the arena and recorded for 3 minutes latencies to approach the object and to reach the object, and all occurrences of locomotion, fear behaviours, and exploration and observation of the object.

\subsection{Statistical analyses}

All data were analysed using Statistica 10 (Stat Soft, Tulsa, OK, U.S.A.). Data for the maternal period were divided into three periods and analysed independently: 1) the afternoon of the post-induction day (PHD2), 2) the beginning of the mothering period (PHD3 and PHD5) and 3) the end of the mothering period (PHD7 andPHD9). General linear models (GLM) were used to describe the influence of brood size on maternal behaviour. General linear mixed models (GLMM) with mother as a random effect were used to analyse the influence of brood size on chicks' behaviour during the mothering period. The distributions were Gaussian for ratio data after logit transformation for no-normality of residuals and Poisson for occurrence data. Chicks' weights were analysed using a linear mixed model (LMM) with similar parameters. Behavioural traits were extracted by computing a Principal Component Analysis (based on Spearman correlations) followed by an orthogonal Varimax rotation to maximize independence between dimensions (Abdi 2003). This analysis yielded scores for all chicks for the behavioural traits for which the influence of brood size was analysed using a LMM, with cages as random factor. The threshold of significance was 0.05 and the tendencies between 0.1 and 0.05 are mentioned.

\section{Results}

\subsection{Maternal behaviour and chicks' behaviour}

\subsubsection{Maternal behaviour}


On the day following induction (PHD2), L mothers emitted significantly more maternal vocalisations (cooing and food calls) than did $\mathrm{S}$ mothers $\left(\mathrm{F}_{1,16}=9.56, \mathrm{P}=0.007\right)$ and tended to emit more calls during the beginning of the mothering period than did $\mathrm{S}$ mothers $\left(\mathrm{F}_{9,16}=3.33, \mathrm{P}=0.087\right)$ (Figure 2).

Brood size did not affect significantly time allocated to warming chicks (GLM, P>0.05; Figure 3a), or the proportion of chicks being warmed $(\mathrm{P}>0.05$; Figure $3 \mathrm{~b})$ during the mothering period.

At the end of the mothering period, $\mathrm{L}$ mothers expressed significantly less covering postures than did $\mathrm{S}$ mothers $\left(\mathrm{F}_{1,16}=4.64, \mathrm{P}=0.047\right.$; Table 2$)$ and trampled their chicks more frequently $\left(\mathrm{F}_{1,16}=6.50, \mathrm{P}=0.021\right.$, Table 2). Brood size did not affect significantly the other behaviours related to maternal care (Table 2). When L mothers were separated from their chicks on PHD11, they tended to emit more distress calls than did $\mathrm{S}$ mothers (GLM: $\left.\mathrm{F}_{1,16}=4.26, \mathrm{P}=0.056\right)$.

\subsubsection{Chicks' behaviour in their home cage}

During the mothering period, the thermoregulation strategies of $\mathrm{L}$ and $\mathrm{S}$ chicks differed during rest periods (Figure 4). L chicks tended to spend more time in a huddle when resting at the beginning of the mothering period (GLMM: $\left.\mathrm{F}_{1,48}=3.58, \mathrm{P}=0.064\right)$ and huddled for a significant greater proportion of resting time at the end of the mothering period $\left(\mathrm{F}_{1,48}=6.95, \mathrm{P}=0.011\right)$ when $\mathrm{S}$ chicks rested alone significantly more frequently $\left(\mathrm{F}_{1,48}=12.93, \mathrm{P}<0.001\right)$.

Chick dispersal indexes did not differ significantly between L and S groups on any of the observation days except on PHD22 when L chicks were dispersed more than S chicks (ID: L: $0.57 \pm 0.03$, S: $0.45 \pm 0.04$, GLM: $\left.\mathrm{F}_{1,16}=10.47, \mathrm{P}<0.01\right)$.

\subsection{Chicks' development}

Brood size did not influence significantly chicks' weights (LMM, all P>0.05, Table 3).

\subsection{Chicks' behavioural traits}


Correlations among chicks' behavioural variables were evaluated using a PCA. We selected a model with two components that accounted for $54 \%$ of the overall variance. The loadings of the behaviours on these two components are described in Figure 4. The first component (32.82\% of the overall variance) presented positive loadings for the number of high observations of the novel object, number of steps and jumps in the openfield, all traits that are correlated with an active emotivity profile. Conversely, negative loadings of this first dimension: latency to reach the object zone in the novel object test and the number of freezing expressed in the openfield test, describe a passive emotivity profile. The second component ( $21.20 \%$ of the overall variance) presented positive loadings for the number of calls during separation tests, number of pecks and cage crossing attempts in the runway test; and negative loadings for latency to emit distress calls when socially isolated (Figure 5). We consider that scores on this second dimensions are correlated with social motivation.

Comparisons of scores obtained by chicks on these two PCA components revealed no significant differences of emotivity scores between $\mathrm{L}$ and $\mathrm{S}$ chicks (LMM, $\mathrm{F}_{1,46}=0.001, \mathrm{P}=0.99$ ), but $\mathrm{L}$ chicks' scored for social motivation were higher than $\mathrm{S}$ chicks' scores $\left(\mathrm{F}_{1,46}=28.51, \mathrm{P}<0.001\right.$, Figure 6).

\section{Discussion}

The results of our investigations of the influence of brood size on adoptive females' maternal behaviour and their chicks' behaviour both during and after the mothering period suggest that mothers of large broods care more for their chicks at the beginning of this period than do mothers of small broods and the reverse at the end of the mothering period. We evidenced that brood size influenced thermoregulation strategies and had consequences on chicks' social behaviour.

\subsection{Influence of brood size on maternal behaviour}

Our results show that brood size does not influence significantly the rates of mothers' warming or aggressive behaviours. However a large brood induced, during the early mothering period, more 
maternal vocalisations, and at the end of this period, more trampling and fewer covering postures during warming.

On the first day of the mothering period, just after induction, mothers of large broods emitted more maternal vocalisations, cooings and food calls. Cooing is by far the most frequent maternal vocalisation emitted during the early part of the mothering period and is even emitted one or two days before hatching. It is usually emitted when a mother begins a phase of activity and moves away from her brood (Guyomarc'h 1974). Food calls are emitted when a mother is foraging. The main effect of these vocalisations is to induce chicks to approach their mother (Wauters et al. 1999; Guyomarc'h 1974). Our results suggest that mothers of large broods emit more vocalisations so as to enhance the cohesion of the mother-chicks group, which is more difficult to maintain because of the greater number of individuals likely to disperse during activity phases. The fact that mothers of large broods tend to emit more calls during the separation test supports this conclusion. Social synchronisation between chicks favours social bonds among siblings and thereby optimises social organisation (Formanek et al. 2011). Group cohesion enhances surveying individuals in natural conditions thus facilitating protection of chicks from predators, and preventing them from getting lost in tall grass.

We could not evidence any effect of brood size on the quantity of warming, the predominant trait of maternal care in this species, as we predicted. Mammal, particularly rodent, mothers of large litters spend less time in their nest and remain there for shorter periods (Grota and Ader 1969, Elwood and Broom 1978). Some altricial bird parents of large broods spend less time in the nest because they must provide more food (Wright and Cuthill 1990; Leckie et al. 2008).

As quail chicks are unable to regulate their temperature during their first days of life (Nichelmann and Tzschentke 2002) they need to be warmed regularly by their mother. With twice as many chicks in our large broods than in our small broods, we think that mothers receive twice as many solicitations for warming, but they do not seem to respond in consequence, in contrast to numerous other species (Pitts et al. 2002; Guerra and Nunes 2001). In our experiment, the number of requests to be warmed appeared to be less important than their distribution over time: quail chicks in a group, are highly synchronized, alternating resting and activity phases (Lumineau et al. 2000, 2001). The presence of a mother increases the intensity of these rhythms (Wauters et al. 2002, Riber et al. 2007). This could explain why mothers 
express a similar amount of warming behaviour regardless of the size of the brood as the beginning of a warming phase is initiated by synchronized chicks. Moreover, despite less heat lost by large broods through huddling, huddling does not allow chicks to store sufficient heat and they must still request warming by their mother (Webb 1993).

However, most trampling and non-covering warming postures were observed towards the end of the mothering period; mothers of large broods then become less attentive and more neglectful so that they appear more rejecting. Similarly, ewes pay less attention to and lick their offspring less when they have twins (Dwyer and Lawrence 1998). We assimilate this to shortening of the rearing period by mothers as for rats that decrease time with their offspring in large litters more rapidly (Grota and Ader 1969). Guerra and Nunes (2001) argued that the decrease of time hamsters spend in contact with their offspring in the nest can be explained by an increase in temperature of the mother-litter system caused in part by a greater number of individuals active at the same time. Moreover, if the number of young exceeds a mother's physical capacities she may neglect her offspring because her energy output would then exceed her capacities. Although quail mothers do not feed their chicks directly, warming them decreases mothers' opportunities to drink or eat. The temperature of a family group increases with number of chicks inducing mothers to reduce their rate of covering postures for less uncomfortable postures.

\subsection{Influence of brood size on chicks' behaviour during the mothering period}

Beyond the influence of brood size on maternal behaviour, brood size influences chicks' behaviour during the mothering period. Chicks in large broods huddle together more frequently, particularly towards the end of the mothering period, whereas chicks in small broods mainly rest alone. We hypothesize two complementary explanations: (1) mothers of large broods would reject their chicks more so that these chicks would need to conserve their body temperature more efficiency and, (2) large broods would allow chicks to reduce their body heat loss (Webb and King 1983). We think that three individuals are not sufficient to allow chicks to warm one another sufficiently, thus making huddling inefficient, contrary to the six chicks in our large broods and Andreasson et al. (2016) recently showed that chicks in small broods, more exposed to the cold, developed their thermoregulatory system faster. However dispersion indices were balanced between broods. Chicks in large broods huddled together 
more during rest phases so they were closer, but they presented a greater propensity to disperse during activity phases than did chicks in small broods. After emancipation, inter-individual distances of chicks in large broods were greater. They appear to adopt a tolerant social structure strategy allowing them to live in groups but limiting attacks due to social proximity (Estevez et al. 2003).

\section{Influence of brood size on chicks' behavioural and morphological development.}

Several authors have discussed the influence of group size on emotivity (Rodenburg and Koene 2007 for a review). Some authors revealed a positive correlation between emotivity and group size that they explained by the fact that competition and aggression increased with the number of individuals (Bilcik et al. 1998). For other authors, on the contrary, emotional responses decrease with increasing group size, the affiliative group having a calming effect against frustration and protection from predators (Takeda et al. 2003; Barnett et al. 1986). Although their mothering was similar, rats in smaller litters were more emotional. Authors suggest that greater competition in large litters constitutes an early form of mild stress, making pups more resistant to future exposure to stressful situations (Dimitsantos et al. 2007). Our experiment revealed no differences of effects due to size of brood: brood size did not influence the proportions of active or passive or reactive emotivity profiles of quail chicks. These profiles are one of the characteristic of proactive and reactive copying styles (Koolhaas et al 1999). Proactive birds are defined as presenting, in stressful situations, active and bold behavioural responses. Conversely, reactive individuals are passive, shy and not very active during stressful events (Koolhaas et al 1999; Cockrem 2007). Several studies report non-genomic transmission of quail mothers' fearfulness to their chicks (Formanek et al. 2009; Richard-Yris et al. 2005). Mothers' emotional reactivity seems to be transmitted to chicks mainly through the level of maternal aggressiveness during the early mothering period (Pittet et al. 2014a, 2014b). This characteristic of care was not affected by brood size thus logically resulting in an absence of differences in reactivity between $\mathrm{L}$ and $\mathrm{S}$ chicks.

By contrast, brood size affected chicks' sociality. Indeed, the social motivation of chicks of large broods was higher as they emitted more distress calls when isolated and made more attempts to reach their conspecifics than did chicks of small broods.

On the one hand, quail mothers influence their chicks' social motivation. In particular, Pittet and 
colleagues (2014a) evidenced a correlation between a mother's level of rejection (notably through the expression of non-covering postures) and her chicks' subsequent social motivation levels, and they presumed that it reinforced the links between individuals in the brood. Similarly, mothers of our large broods expressed more rejection at the end of the mothering period, and chicks in large broods adopted more allo-warming than did chicks in small broods. The influence of brood size on chicks' sociality could be mediated by maternal rejection towards the end of the mothering period, increasing the strength of the social link that chicks develop among themselves. We think that brood size affected chicks' sociality directly independently of maternal care, as a richer social environment provides opportunities to develop social relationships with more individuals and so more complex relationships (Schweitzer et al. 2011). Therefore these individuals react more strongly to separation and try more to maintain contact with conspecifics.

In conclusion, quail brood size influences mothers during the mothering period: frequency of maternal vocalisations increased at the beginning of the mothering period and warming decreased towards the end of the period in large broods, indicating earlier rejection. This impacted the relationships between chicks of large brood that huddled more when resting. Belonging to a precocial species, mother quail do not feed their chicks directly, and this reduces the charge of parental investment related to the number of chicks compared to altricial birds. Quail's main mothering role is to warm chicks and ensure their protection against predators. For this, mothers adapt their communication and increase the number of vocalisations when brood size increases to maintain strong social cohesion within their family group. Chicks' behavioural development, particular their sociality, is influenced by brood size. Now, furthers investigations are necessary to determine effects on maternal behavior, if size group increases so that social bonds were weaker and could disorganize social cohesion, or if density brood decreases so that dispersion between siblings could be higher. 
Acknowledgements

We are grateful to Maxime Hervé for statistical help and Ann Cloarec for reading this article.

\section{References}

Abdi, H., 2003. Factor rotations in factor analyses. Encycl. Res. Methods Soc. Sci. Sage Thousand Oaks CA 792-795.

Andreasson, F., Nord, A., Nilsson, J.-Å., 2016. Brood size constrains the development of endothermy in blue tits. J. Exp. Biol. 219, 2212-2219. doi:10.1242/jeb.135350

Angelier, F., Weimerskirch, H., Dano, S., Chastel, O., 2007. Age, experience and reproductive performance in a long-lived bird: a hormonal perspective. Behav. Ecol. Sociobiol. 61, 611-621. doi:10.1007/s00265-006-0290-1

Barnett, J.L., Hemsworth, P.H., Winfield, C.G., Hansen, C., 1986. Effects of social environment on welfare status and sexual behaviour of female pigs. I. Effects of group size. Appl. Anim. Behav. Sci. 16, 249-257. doi:10.1016/0168-1591(86)90117-6

Bilčík, B., Keeling, L.J., Newberry, R.C., 1998. Effect of group size on tonic immobility in laying hens. Behav. Processes 43, 53-59. doi:10.1016/S0376-6357(97)00081-8

Champagne, F.A., Francis, D.D., Mar, A., Meaney, M.J., 2003. Variations in maternal care in the rat as a mediating influence for the effects of environment on development. Physiol. Behav. 79, 359-371. doi:10.1016/S0031-9384(03)00149-5

Clark, L., 1985. Consequences of homeothermic capacity of nestlings on parental care in the european starling. Oecologia 65, 387-393. doi:10.1007/BF00378914

Cockrem, J.F., 2007. Stress, corticosterone responses and avian personalities. J. Ornithol. 148, 169-178. doi:10.1007/s10336-007-0175-8

Dimitsantos, E., Escorihuela, R.M., Fuentes, S., Armario, A., Nadal, R., 2007. Litter size affects emotionality in adult male rats. Physiol. Behav. 92, 708-716. doi:10.1016/j.physbeh.2007.05.066 
Dingemanse, N.J., Both, C., Drent, P.J., Tinbergen, J.M., 2004. Fitness consequences of avian personalities in a fluctuating environment. Proc. R. Soc. B Biol. Sci. 271, 847-852. doi:10.1098/rspb.2004.2680

Dwyer, C.M., Lawrence, A.B., 1998. Variability in the expression of maternal behaviour in primiparous sheep: Effects of genotype and litter size. Appl. Anim. Behav. Sci. 58, 311-330. doi:10.1016/S01681591(97)00148-2

Elwood, R.W., Broom, D.M., 1978. The influence of litter size and parental behaviour on the development of Mongolian gerbil pups. Anim. Behav. 26, 438-454.

Estevez, I., Keeling, L.J., Newberry, R.C., 2003. Decreasing aggression with increasing group size in young domestic fowl. Appl. Anim. Behav. Sci. 84, 213-218. doi:10.1016/j.applanim.2003.08.006 Formanek, L., Richard-Yris, M.A., Houdelier, C., Lumineau, S., 2011. Rhythmic birds show a better social integration than arrhythmic birds. Chronobiol. Int. 28, 48-57.

Formanek, L., Richard-Yris, M.A., Houdelier, C., Lumineau, S., 2009. Epigenetic maternal effects on endogenous rhythms in precocial birds. Chronobiol. Int. 26, 396-414.

Gaioni, S.J., Hoffman, H.S., Klein, S.H., DePaulo, P., 1977. Distress calling as a function of group size in newly hatched ducklings. J. Exp. Psychol. Anim. Behav. Process. 3, 335-342. doi:10.1037/00977403.3.4.335

Grota, L.J., Ader, R., 1969. Continuous recording of maternal behaviour in Rattus norvegicus. Anim. Behav. 17, 722-729.

Guerra, R.F., Nunes, C.R. de O., 2001. Effects of litter size on maternal care, body weight and infant development in golden hamsters (Mesocricetus auratus). Behav. Processes 55, 127-142.

Guyomarc'h, J., 1974. Les vocalisations des Gallinacés — structure des sons et des répertoires. Ontogenèse motrice et acquisition de leur sémantique. Thesis: Université de Rennes, Rennes.

Guyomarc'h, J.-C., Saint-Jalme, M., 1986. La reproduction chez la caille des blés (Coturnix C. coturnix). II: Croissance et développement sexuel des jeunes. Gibier Faune Sauvage 3, 281-295.

Harding, A.M.A., Kitaysky, A.S., Hamer, K.C., Hall, M.E., Welcker, J., Talbot, S.L., Karnovsky, N.J., Gabrielsen, G.W., Grémillet, D., 2009. Impacts of experimentally increased foraging effort on the family: offspring sex matters. Anim. Behav. 78, 321-328. doi:10.1016/j.anbehav.2009.05.009 
Houdelier, C., Pittet, F., Guibert, F., de, M.E., Lumineau, S., 2013. Non-genetic inheritance in birds: transmission of behaviour from mother to offspring. Non-Genet. Inherit. 1, 62-68. doi:10.2478/ngi2013-0007

Johnson, E.J., Best, L.B., 1982. Factors affecting feeding and brooding of gray catbird nestlings. The Auk 99, 148-156. doi:10.2307/4086031

Jones, B.R., 1987. Fear and fear responses: A hypothetical consideration. Med. Sci. Res. 15, 1287-1290. Jones, R.B., Bessei, W., Faure, J.M., 1982. Aspects of "fear" in Japanese quail chicks (Coturnix coturnix Japonica) genetically selected for different levels of locomotor activity. Behav. Processes 7, 201-210. doi:10.1016/0376-6357(82)90035-3

Jones, R.B., Harvey, S., 1987. Behavioural and adrenocortical responses of domestic chicks to systematic reductions in group size and to sequential disturbance of companions by the experimenter. Behav. Processes 14, 291-303. doi:10.1016/0376-6357(87)90075-1

Koolhaas, J.M., Korte, S.M., De Boer, S.F., Van Der Vegt, B.J., Van Reenen, C.G., Hopster, H., De Jong, I.C., Ruis, M.A.W., Blokhuis, H.J., 1999. Coping styles in animals: current status in behavior and stress-physiology. Neurosci. Biobehav. Rev. 23, 925-935.

Leckie, F.M., Arroyo, B.E., Thirgood, S.J., Redpath, S.M., 2008. Parental differences in brood provisioning by Hen Harriers Circus cyaneus: Capsule Females varied their provisioning patterns according to brood age and brood size, whereas males did not. Bird Study 55, 209-215. doi:10.1080/00063650809461524

Lepage, D., Gauthier, G., Desrochers, A., 1998. Larger clutch size increases fledging success and offspring quality in a precocial species. J. Anim. Ecol. 67, 210-216. doi:10.1046/j.13652656.1998.00182.x

Lopatina, O., Inzhutova, A., Pichugina, Y.A., Okamoto, H., Salmina, A.B., Higashida, H., 2011. Reproductive experience affects parental retrieval behaviour associated with increased plasma oxytocin levels in wild-type and Cd38-knockout mice. J. Neuroendocrinol. 23, 1125-1133. doi:10.1111/j.13652826.2011.02136.x 
Lumineau, S., Guyomarc'h, C., Richard, J.-P., 2001. Ultradian rhythm of activity in japanese quail groups under semi-natural conditions during ontogeny: functional aspects and relation to circadian rhythm. Biol. Rhythm Res. 32, 373-400. doi:10.1076/brhm.32.3.373.1339

Lumineau, S., Guyomarc'h, C., Richard, J.-P., 2000. Ontogeny of the ultradian rhythm of activity in japanese quail. Chronobiol. Int. 17, 767-776. doi:10.1081/CBI-100102112

Mills, A.D., Faure, J.M., 1991. Divergent selection for duration of tonic immobility and social reinstatement behavior in Japanese quail (Coturnix coturnix japonica) chicks. J. Comp. Psychol. 105, $25-38$.

Nichelmann, M., Tzschentke, B., 2002. Ontogeny of thermoregulation in precocial birds. Comp. Biochem. Physiol. A. Mol. Integr. Physiol. 131, 751-763. doi:10.1016/S1095-6433(02)00013-2

Paasivaara, A., Pöysä, H., 2007. Survival of common goldeneye Bucephala clangula ducklings in relation to weather, timing of breeding, brood size, and female condition. J. Avian Biol. 38, 144-152. doi:10.1111/j.2007.0908-8857.03602.x

Pittet, F., Coignard, M., Houdelier, C., Richard-Yris, M.-A., Lumineau, S., 2013a. Effects of maternal experience on fearfulness and maternal behaviour in a precocial bird. Anim. Behav. 85, 797-805. doi:10.1016/j.anbehav.2013.01.026

Pittet, F., Coignard, M., Houdelier, C., Richard-Yris, M.-A., Lumineau, S., 2012. Age affects the expression of maternal care and subsequent behavioural development of offspring in a precocial bird. PLoS ONE 7, e36835. doi:10.1371/journal.pone.0036835

Pittet, F., Houdelier, C., de Margerie, E., Le Bot, O., Richard-Yris, M.-A., Lumineau, S., 2014a. Maternal styles in a precocial bird. Anim. Behav. 87, 31-37. doi:10.1016/j.anbehav.2013.10.025

Pittet, F., Houdelier, C., Le Bot, O., Leterrier, C., Lumineau, S., 2014b. Fearfulness affects quail maternal care and subsequent offspring development. PLoS ONE 9, e102800. doi:10.1371/journal.pone.0102800

Pittet, F., Le Bot, O., Houdelier, C., Richard-Yris, M.-A., Lumineau, S., 2013b. Motherless quail mothers display impaired maternal behavior and produce more fearful and less socially motivated offspring. Dev. Psychobiol. n/a-n/a. doi:10.1002/dev.21129 
Pitts, A.D., Weary, D.M., Fraser, D., Pajor, E.A., Kramer, D.L., 2002. Alternative housing for sows and litters. Part 5. Individual differences in the maternal behaviour of sows. Appl. Anim. Behav. Sci. 76, 291-306. doi:10.1016/S0168-1591(02)00012-6

Pöysä, H., Virtanen, J., Milonoff, M., 1997. Common goldeneyes adjust maternal effort in relation to prior brood success and not current brood size. Behav. Ecol. Sociobiol. 40, 101-106. doi:10.1007/s002650050321

Priestnall, R., 1972. Effects of litter size on the behaviour of lactating female mice (Mus musculus). Anim. Behav. 20, 386-394. doi:10.1016/S0003-3472(72)80063-0

Riber, A.B., Nielsen, B.L., Ritz, C., Forkman, B., 2007. Diurnal activity cycles and synchrony in layer hen chicks (Gallus gallus domesticus). Appl. Anim. Behav. Sci. 108, 276-287. doi:10.1016/j.applanim.2007.01.001

Richard-Yris, M.A., 1994. Comportement parental chez les gallinacées: Importance du facteur émotivité dans la vitesse d'émergence des réponses parentales. Apport du modèle caille japonaise., in: Comportement et Bien-Être Animal. Picard M., Porter R.H., Signoret J.D., Paris, pp. 61-77.

Richard-Yris, M.A., Michel, N., Bertin, A., 2005. Nongenomic inheritance of emotional reactivity in Japanese quail. Dev. Psychobiol. 46, 1-12.

Rodenburg, T.B., Koene, P., 2007. The impact of group size on damaging behaviours, aggression, fear and stress in farm animals. Appl. Anim. Behav. Sci., Too many, too few: The effects of group size and density in captive animals 103, 205-214. doi:10.1016/j.applanim.2006.05.024

Royama, T.., 1966. Factors governing feeding rate, food requirement and brood size of nestling great tits Parus major. Ibis 108, 313-347. doi:10.1111/j.1474-919X.1966.tb07348.x

Royle, N.J., Smiseth, P.T., Kölliker, M., 2012. The evolution of parental care. Oxford University Press. Safriel, U.N., 1975. On the significance of clutch size in nidifugous birds. Ecology 56, 703-708. doi:10.2307/1935505

Sandercock, B.K., 1994. The effect of manipulated brood size on parental defence in a precocial bird, the willow ptarmigan. J. Avian Biol. 25, 281-286. doi:10.2307/3677275

Schindler, M., Lamprecht, J., 1987. Increase of parental effort with brood size in a nidifugous bird. The Auk 104, 688-693. 
Schweitzer, C., Lévy, F., Arnould, C., 2011. Increasing group size decreases social bonding in young Japanese quail, Coturnix japonica. Anim. Behav. 81, 535-542. doi:10.1016/j.anbehav.2010.11.017 Smiseth, P.T., Moore, A.J., 2002. Does resource availability affect offspring begging and parental provisioning in a partially begging species? Anim. Behav. 63, 577-585. doi:10.1006/anbe.2001.1944 Takeda, K., Sato, S., Sugawara, K., 2003. Familiarity and group size affect emotional stress in Japanese black heifers. Appl. Anim. Behav. Sci. 82, 1-11. doi:10.1016/S0168-1591(03)00039-X

Turcotte, Y., Bédard, J., 1989. Shared parental investment, parent-offspring conflict and brood size in greater snow geese. Anim. Behav. 38, 703-706.

Walsh, H., 1978. Food of nestling purple martins. Wilson Bull. 90, 248-260.

Walter, J.R., 1982. Parental behavior in lapwings (Charadriidae) and its relationships with clutch sizes and mating systems. Evolution 36, 1030-1040. doi:10.2307/2408080

Wauters, A., Richard-Yris, M., Talec, N., 2002. Maternal influences on feeding and general activity in domestic chicks. Ethology 108, 529-540. doi:10.1046/j.1439-0310.2002.00793.x

Wauters, A.M., Richard-Yris, M.A., Pierre, J.S., Lunel, C., Richard, J.P., 1999. Influence of chicks and food quality on food calling in broody domestic hens. Behaviour 136, 919-933. doi:10.1163/156853999501649

Webb, D.R., 1993. Maternal-nestling contact geometry and heat transfer in an altricial bird. J. Therm. Biol. 18, 117-124. doi:10.1016/0306-4565(93)90024-N

Webb, D.R., King, J.R., 1983. Heat-transfer relations of avian nestlings. J. Therm. Biol. 8, 301-310. doi:10.1016/0306-4565(83)90013-X

Williams, T.D., Loonen, M.J.J.E., Cooke, F., 1994. Fitness consequences of parental behavior in relation to offspring number in a precocial species: the lesser snow goose. The Auk 111, 563-572.

Wright, J., Cuthill, I., 1990. Manipulation of sex differences in parental care: the effect of brood size. Anim. Behav. 40, 462-471. doi:10.1016/S0003-3472(05)80526-3

Yasukawa, K., Mcclure, J.L., Boley, R.A., Zanocco, J., 1990. Provisioning of nestlings by male and female red-winged blackbirds, Agelaius phoeniceus. Anim. Behav. 40, 153-166. doi:10.1016/S00033472(05)80675-X 


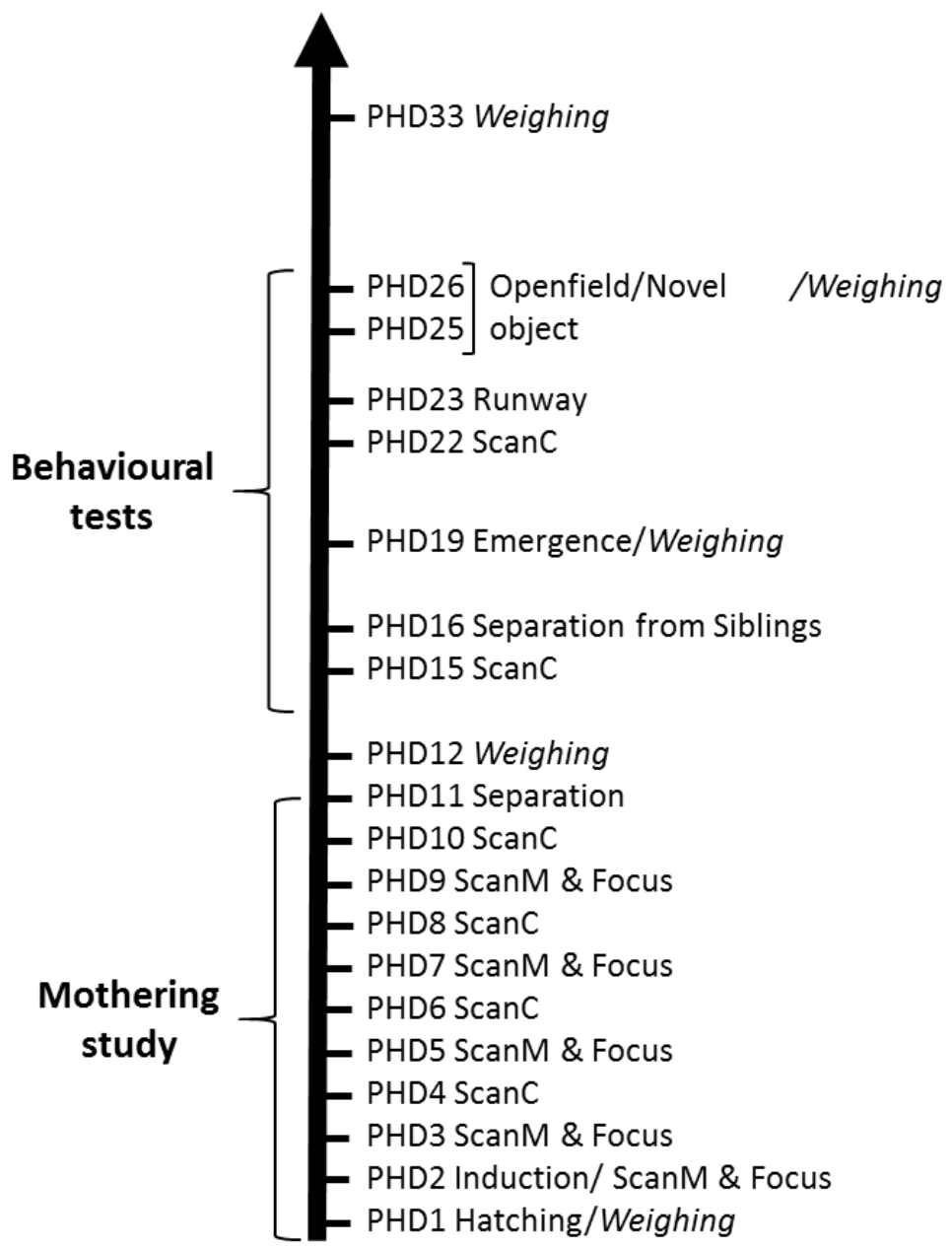

Figure 1: Timeline of the observations during mothering period and tests after separation from mother. PHD: Post Hatching Day. ScanM = scans for mother; ScanC = scan for chicks. 


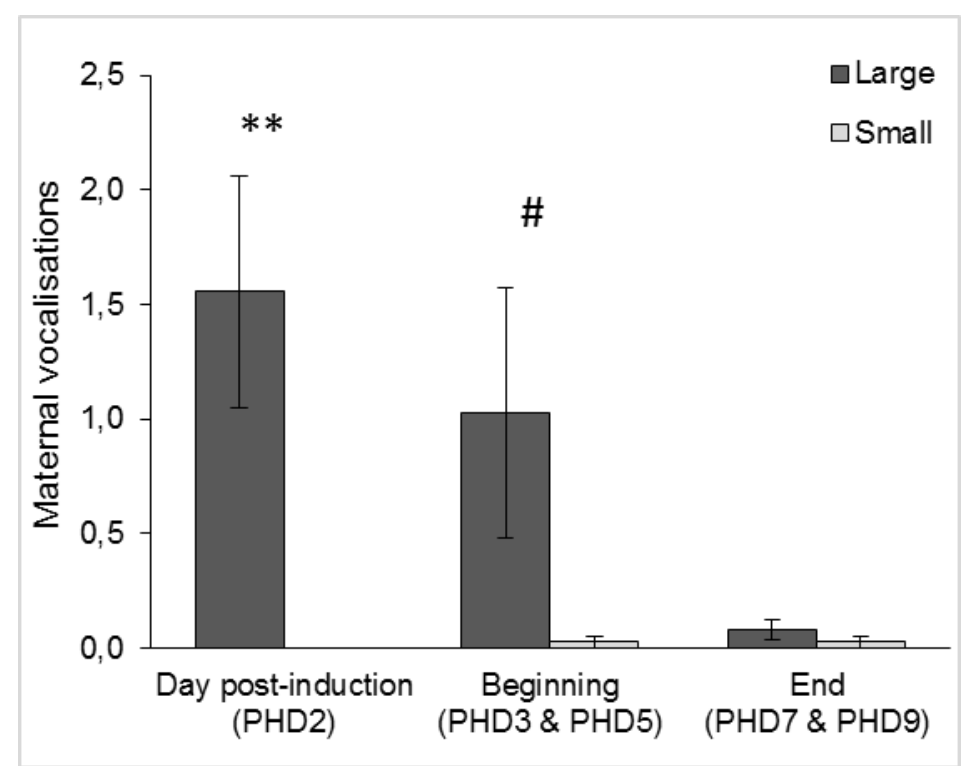

Figure 2: Maternal vocalisations (cooing and food calls) per 10min duration focal samples, for $\mathrm{L}$ and $\mathrm{S}$ broods on the day of induction and at the beginning and end of the mothering period (mean \pm SE). GLM: $\#: \mathrm{P}<0.10$ and $* *: \mathrm{P}<0.01$ 


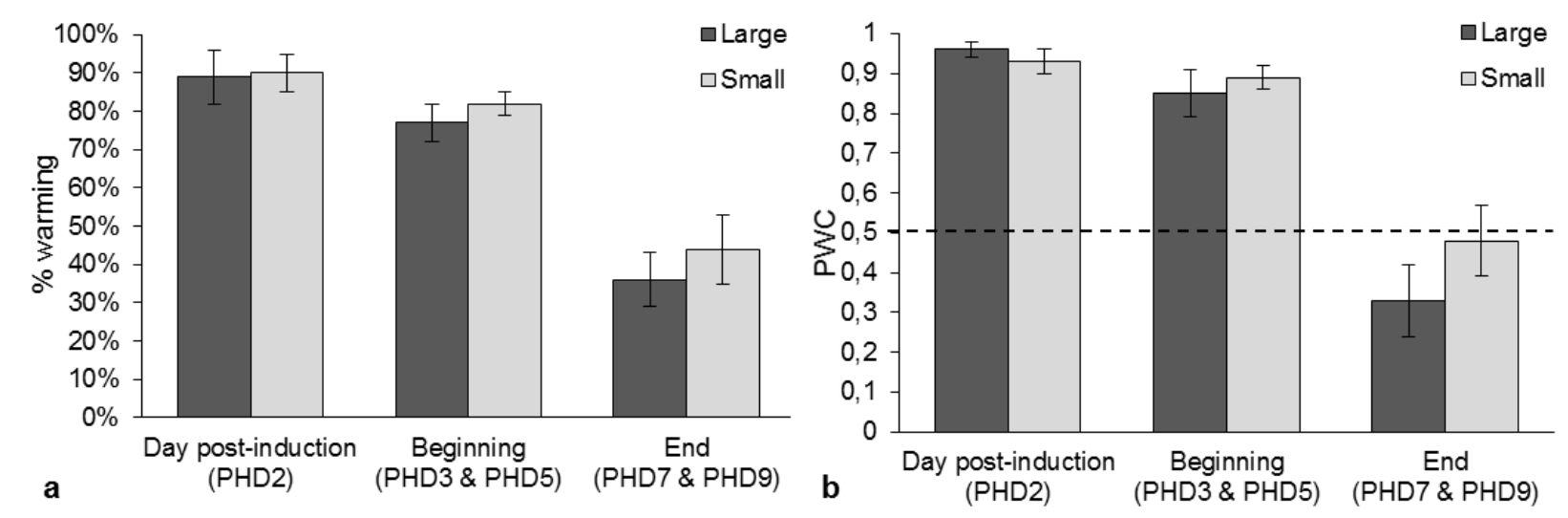

Figure 3: Maternal behaviour: (a) time spent warming (in percent, mean \pm SE) and (b) proportion of chicks warmed (PWC) on the day of induction and at the beginning and end of the mothering period in L and S broods. GLM. Dashed line: half of the brood warmed. 


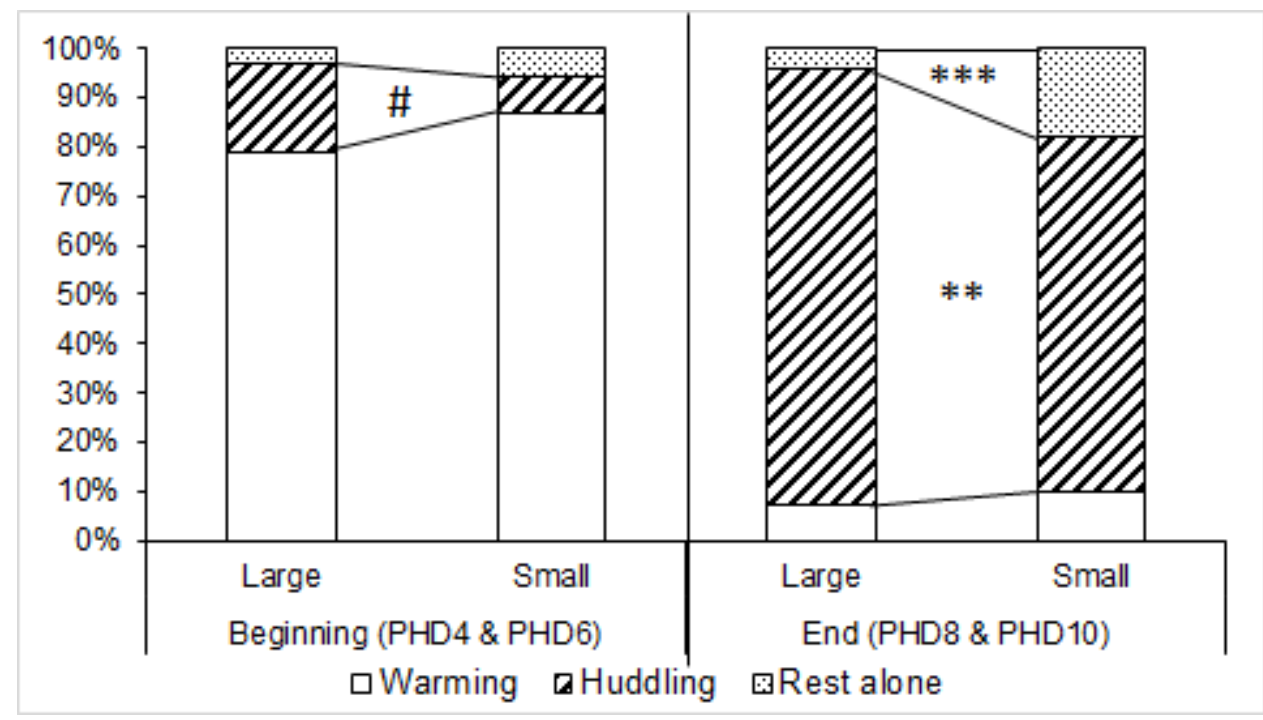

Figure 4: Resting (in \% of total time spent resting): warming, huddling and resting alone by chicks in large or small broods at the beginning (PHD4 \& PHD6) and the end (PHD8 \& PHD10) of the mothering period. GLMM: \#: $\mathrm{P}<0.10, * *: \mathrm{P}<0.01$ and $* * *: \mathrm{P}<0.001$ 


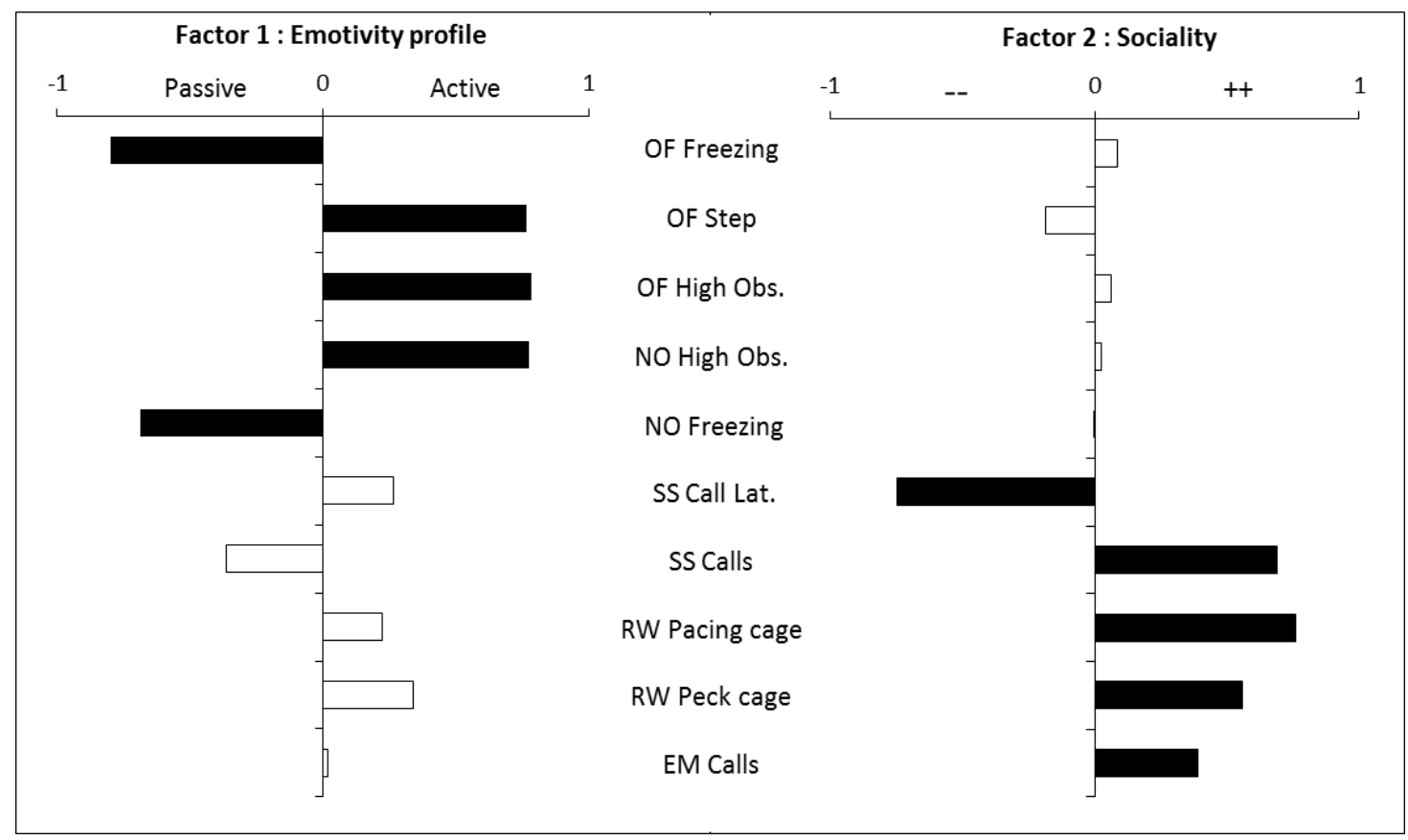

Figure 5: Chicks' behavioural traits described by the 10 main test variables on the first two axes of the PCA with varimax rotation. OF: Openfield; NO: Novel Object; SS: Siblings Separation, RW: Runway test \& EM: Emergency test. The first factor represents emotivity variables for the passive and active emotivity profiles. The second factor represents sociality with "++" for more social and "- -"for less social motivation. Black bars: variable loadings $>|0.5|$. 


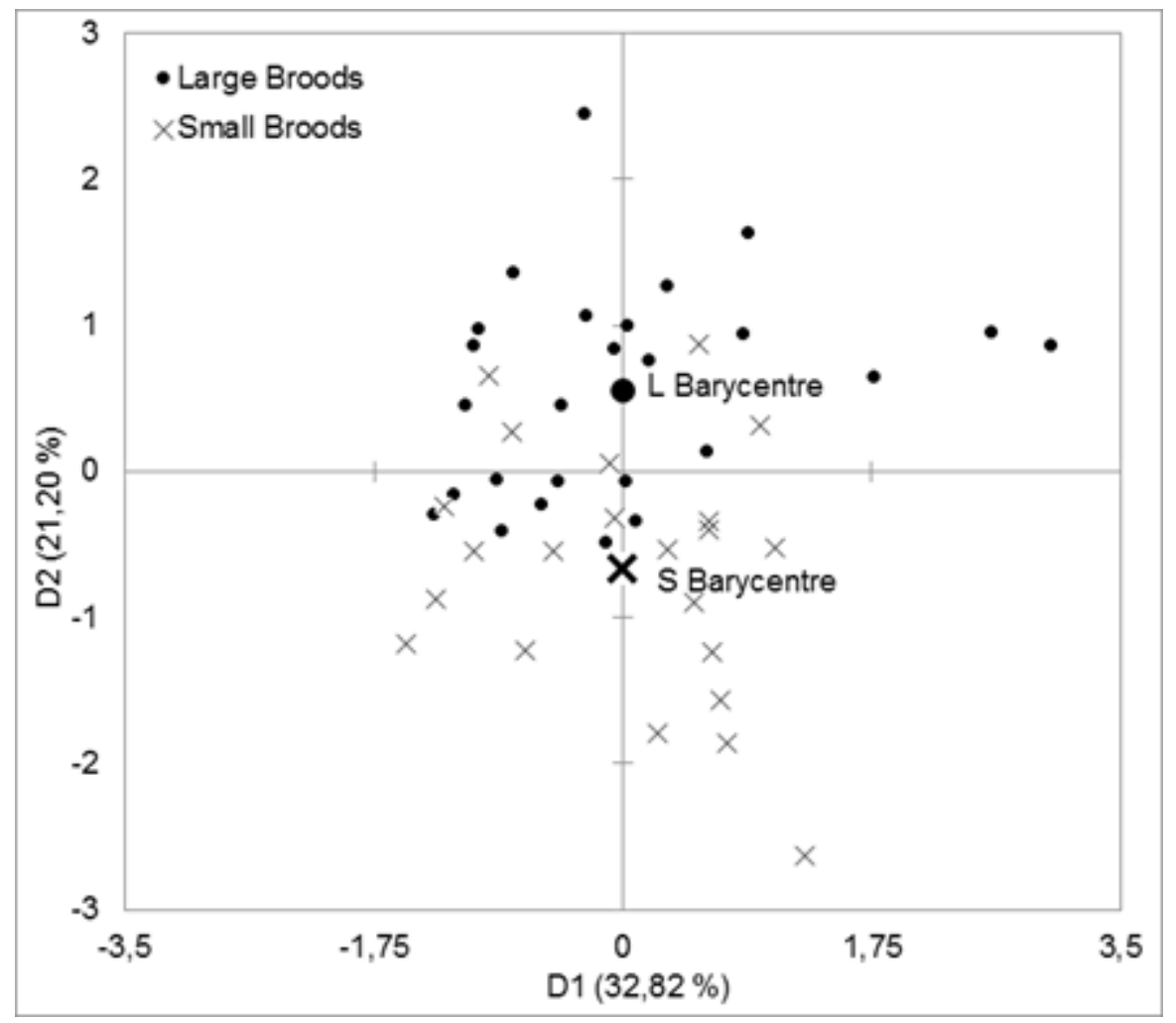

Figure 6: Scores obtained by chicks in large broods (L) and chicks in small broods (S) according to the two axes of behavioural traits from the PCA with varimax rotation. 
Table 1: Description of observations and variables recorded during the mothering period.

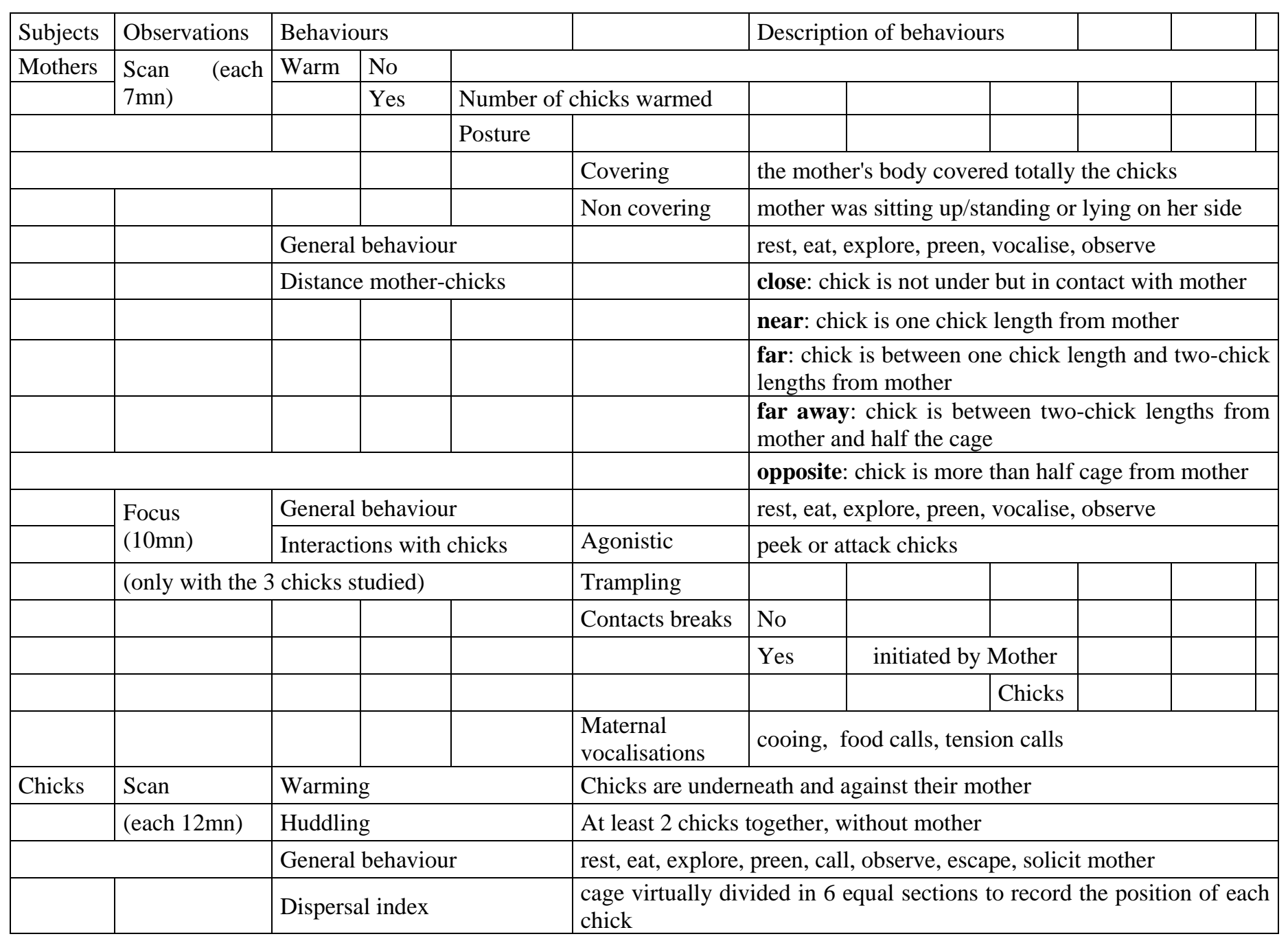


Table 2: Maternal behaviour parameters (mean \pm SE) for large and small broods. PHD: Post Hatching

Day. GLM *: $\mathrm{P}<0.05$. Bold values are significant.

\begin{tabular}{|c|c|c|c|c|c|c|c|}
\hline \multirow{3}{*}{\multicolumn{2}{|c|}{ Variables }} & \multicolumn{6}{|l|}{ GLM } \\
\hline & & \multicolumn{2}{|c|}{ Post induction day (PHD2) } & \multicolumn{2}{|c|}{ Beginning (PHD3 \& PHD5) } & \multicolumn{2}{|c|}{ End (PHD7 \& PHD9 } \\
\hline & & Large & Small & Large & Small & Large & Small \\
\hline \multirow{6}{*}{$\begin{array}{l}\text { Maternal } \\
\text { behaviours }\end{array}$} & \begin{tabular}{|l} 
Covering \\
postures $(\%)$
\end{tabular} & $0.99 \pm 0.01$ & $0.99 \pm 0.01$ & $0,93 \pm 0,12$ & $0,94 \pm 0,04$ & $\mathbf{0 , 8 7} \pm \mathbf{0 , 0 8}$ & $\forall 0,95 \pm 0,05$ \\
\hline & Mothers' breaks & $0.67 \pm 0.33$ & $2.00 \pm 1.10$ & $4,00 \pm 3,16$ & $5,89 \pm 3,69$ & $2,78 \pm 2,39$ & $3,78 \pm 3,03$ \\
\hline & Chicks' breaks & $2.00 \pm 0.45$ & $1.00 \pm 0.63$ & $2,56 \pm 1,88$ & $1,89 \pm 2,57$ & $2,00 \pm 3,77$ & $1,33 \pm 2,18$ \\
\hline & \begin{tabular}{|ll}
$\begin{array}{l}\text { Distance with } \\
\text { chicks }\end{array}$ & wick \\
\end{tabular} & $0.08 \pm 0.01$ & $0.09 \pm 0.01$ & $0,19 \pm 0,11$ & $0,16 \pm 0,07$ & $0,65 \pm 0,17$ & $0,59 \pm 0,21$ \\
\hline & Aggressions & - & $0.33 \pm 0.33$ & $2,33 \pm 7,00$ & $3,00 \pm 6,57$ & $2,33 \pm 4,82$ & $1,89 \pm 2,98$ \\
\hline & Trampling & - & $0.22 \pm 0.15$ & $1,00 \pm 1,58$ & $1,67 \pm 2,69$ & $1,89 \pm 1,54$ & $0,44 \pm 0,73$ \\
\hline \multirow{5}{*}{$\begin{array}{l}\text { General } \\
\text { activity }(\%)\end{array}$} & Activity & $0.10 \pm 0.02$ & $0.08 \pm 0.02$ & $0,20 \pm 0,11$ & $0,14 \pm 0,07$ & $0,40 \pm 0,11$ & $0,38 \pm 0,19$ \\
\hline & Locomotion & $0.04 \pm 0.07$ & $0.06 \pm 0.07$ & $0,20 \pm 0,14$ & $0,13 \pm 0,08$ & $0,66 \pm 0,19$ & $0,54 \pm 0,28$ \\
\hline & Feeding & $0.09 \pm 0.03$ & $0.09 \pm 0.03$ & $0,09 \pm 0,05$ & $0,15 \pm 0,10$ & $0,05 \pm 0,06$ & $0,09 \pm 0,11$ \\
\hline & Maintenance & $0.10 \pm 0.04$ & $0.16 \pm 0.04$ & $0,17 \pm 0,06$ & $0,21 \pm 0,11$ & $0,14 \pm 0,11$ & $0,20 \pm 0,14$ \\
\hline & Exploration & $0.08 \pm 0.02$ & $0.09 \pm 0.02$ & $0,03 \pm 0,02$ & $0,04 \pm 0,02$ & $0,01 \pm 0,01$ & $0,02 \pm 0,03$ \\
\hline
\end{tabular}


Table 3: Chicks' weights (mean \pm SE, in grammes) for L and S broods on PHD12, PHD19, PHD26 \& PHD33. LMM tests.

\begin{tabular}{|l|l|l|l|l|l|}
\hline Days & & PHD12 & PHD19 & PHD26 & PHD33 \\
\hline Weight & Large & $64.66 \pm 2.14$ & $126.96 \pm 4.03$ & $200.85 \pm 5.75$ & $256.15 \pm 4.85$ \\
\hline & Small & $64.15 \pm 2.27$ & $121.43 \pm 4.01$ & $198.84 \pm 4.58$ & $254.44 \pm 5.22$ \\
\hline \multicolumn{2}{|l}{ LMM (P) } & 0.81 & 0.87 & 0.34 & 0.79 \\
\hline
\end{tabular}

